\title{
Five-hour Oral Glucose Tolerance Test in Obese Children
}

\author{
J. M. COURT, MARJORIE DUNLOP, „ INGRID LEONARD, and R. F. LEONARD \\ From the Department of Paediatrics, University of Melbourne, and the Department of Pathology, Royal Children's \\ Hospital, Parkville, Victoria, Australia
}

\begin{abstract}
Court, J. M., Dunlop, M., Leonard, I., and Leonard, R. F. (1971). Archives of Disease in Childhood, 46, 791. Five-hour oral glucose tolerance test in obese children. Concentrations of blood glucose, plasma free fatty acids, and plasma glycerol during a 5-hour oral glucose tolerance test on 46 obese children are reported.

Seven children had unequivocally impaired glucose tolerance. However in the group as a whole, there was a delay in return of blood glucose to baseline levels after oral glucose, 27 children $(60 \%)$ having a blood glucose concentration greater than $110 \mathrm{mg} / 100 \mathrm{ml}$ at 2 hours. It was concluded that some degree of glucose intolerance is common in childhood obesity. No relation was seen among the following: impairment of glucose tolerance and age, degree or duration of obesity, or family history of diabetes.

Fasting plasma free fatty acids and glycerol concentrations were high (mean \pm $1 \mathrm{SD}, 1030 \pm 221 \mu \mathrm{Eq} /$ litre FFA and $121 \pm 44 \mu \mathrm{mol} / \mathrm{l}$. glycerol). For all children, concentrations of FFA and glycerol decreased during the first hour after glucose, though minimal levels were not reached until 90-120 minutes (mean $\pm 1 S D, 395 \pm$ $170 \mu \mathrm{Eq} /$ litre FFA, $77 \pm 24 \mu \mathrm{mol} / \mathrm{l}$. glycerol). For those children (27) who had raised blood glucose at 2 hours, there was a positive correlation between fasting plasma glycerol concentration and glucose tolerance sum, suggesting that impaired glucose tolerance was associated with increased basal lipolysis.
\end{abstract}

Clinical interest in early childhood obesity has increased with the recognition that its prognosis is poor and that a high proportion of obese children become obese adults (Mullins, 1958). The association of adult obesity with diabetes mellitus is well established (Gordon, 1962), and impaired glucose tolerance and raised fasting levels of plasma free fatty acids (FFA) have been documented in obese adults (Morse et al., 1960; Schalch and Kipnis, 1965). There have been relatively few similar studies in obese children however, and this study has been made to gain information on whether impaired glucose tolerance may be present early in the course of some cases of obesity, or whether it is more likely to be the late result of prolonged obesity.

It has been suggested by Gordon, Goldberg, and Chosy (1963) and Kneebone (1965) that in some forms of obesity there is impaired response of FFA to glucose administration. This led to the

Received 6 April 1971.

^Supported in part by a grant from Richardson Merrill Pty Ltd. concept of a metabolic basis for such obesity. Measurements of FFA and glycerol values during a 5-hour glucose tolerance test were made to test this concept, to study both the question of whether FFA response to glucose is impaired in obese children, and whether differing types of response may occur in children with distinct clinical characteristics. Such differences could support the concept of a metabolic basis for some forms of obesity.

\section{Clinical Material}

46 obese children, aged from 2 to 15 years with a mean age of 10.6 years, were studied. There were 24 boys and 22 girls, and duration of their obesity ranged from 2 to 15 years with a mean of 6.5 years. 15 had developed obesity in the first 2 years of life, and all but one had become obese in the early childhood years before puberty.

Almost all were substantially obese as judged by skinfold thickness measurements at multiple sites (Tanner and Whitehouse, 1962). The degree to which they were overweight, judged by expressing 
their actual weight as a percentage of their expected weight for height, age, and sex on centile charts, ranged from $15 \%$ to $176 \%$, with a mean of $58 \%$ overweight.

38 of the children had a family history of obesity among first, second, or third degree relatives, 21 on both maternal and paternal sides of the family. 17 had a family history of diabetes mellitus.

\section{Methods}

The children were admitted to the metabolic ward during the afternoon before the investigation, having been instructed to eat ad libitum during the preceding week. After an overnight fast of 12 to 13 hours an oral glucose tolerance test was performed. For this a standard dose of glucose, $2.2 \mathrm{~g} / \mathrm{kg}$ body weight, to a maximum of $50 \mathrm{~g}$, was given.

Venous blood samples were obtained from an indwelling catheter in a superficial arm vein. Three fasting samples were obtained during a 1-hour period before glucose was administered, and subsequent samples were obtained at $\frac{1}{2}$-hourly intervals for 2 hours and then hourly for a total of 5 hours after the glucose load.

On each sample estimates were made of glucose using a glucose oxidase method, FFA (Novák, 1965), and glycerol (Laurell and Tibbling, 1968).

\section{Results and Discussion}

The results of the 5 hour GTT and mean values for glucose, FFA, and glycerol with standard deviations are shown in Fig. 1.

The glucose tolerance sum (GTS 0-2 hours), an index of glucose tolerance which summates blood glucose values at fasting, 30,60, and 120 minutes after glucose administration, was used to compare our results with accepted criteria of normal glucose tolerance. Danowski et al. (1970) have employed this measure of glucose tolerance as one in which GTS 0-2 hours values of less than 500 meet the standards of normality proposed by Fajans and Conn (1959) and those accepted by other international authorities. Values between 500-650 are regarded as equivocal by these criteria. In the present study, 7 (15\%) subjects had GTS values of 500-620 and thus fell in the equivocal range. None was in the range diagnostic of diabetes, the majority of cases fulfilling the requirements for normal glucose tolerance. On the other hand, 27 $(60 \%)$ of these obese children had an equivocal glucose value at 120 minutes. This is expressed in Fig. 2 in which mean values for glucose plus $1 \mathrm{SD}$ are shown in comparison with the range of values (mean $\pm 1 S D$ ) encountered in a normal population by Fajans and Conn (1965). These authors noted a similar type of attentuated response to glucose

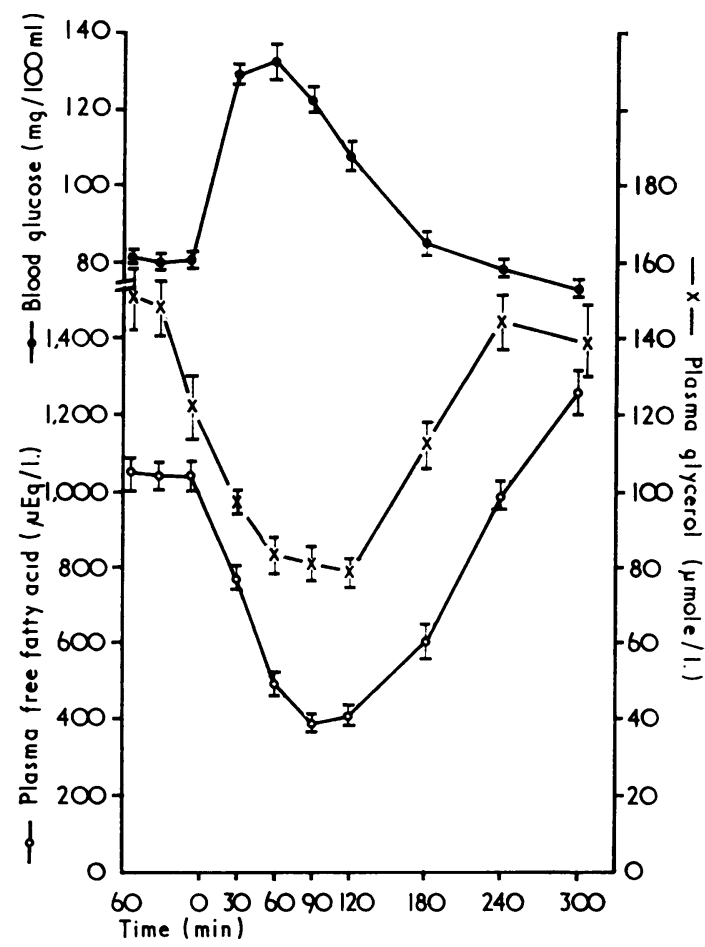

Fig. 1.-Blood glucose, plasma FFA, and plasma glycerol measured after oral glucose at $T=0$ minutes (mean \pm standard error).

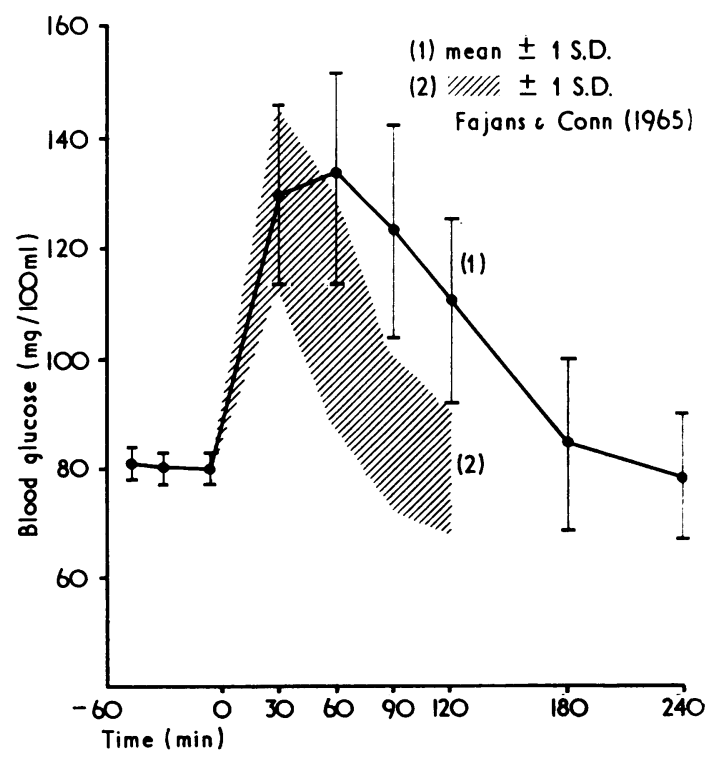

FIG. 2.-Blood glucose values during oral GTT in obese children compared with the range of a normal population. 
administration in the non-diabetic offspring of diabetic parents. However, summation of glucose values showed no sharp delineation between normal and abnormal carbohydrate tolerance in asymptomatic relatives of diabetics. In the present study neither the distribution of the values for GTS 0-2 hours nor the glucose values at 120 minutes differed when children were compared on the basis of diabetic family history. The table shows similar results in glucose tolerance for children with or without family incidence of diabetes mellitus.

\section{TABLE}

Comparison of Glucose Tolerance of Children with or without Family History of Diabetes Mellitus

\begin{tabular}{c|c|c}
\hline $\begin{array}{c}\text { Family History of } \\
\text { Diabetes Mellitus }\end{array}$ & $\begin{array}{c}\star \text { GTS (0-2 hr) } \\
(\text { mean } \pm 1 \mathrm{SD})\end{array}$ & $\begin{array}{c}\text { Blood Glucose } \\
(2-\mathrm{hr} \text { value) mg/ } \\
100 \mathrm{ml} \text { (mean } \pm 1 \mathrm{SD}\end{array}$ \\
\hline $\begin{array}{c}\text { Yes } \\
\mathrm{n}=17\end{array}$ & $447 \pm 48$ & $104 \pm 19$ \\
\hline $\begin{array}{l}\text { No } \\
\mathrm{n}=29\end{array}$ & $454 \pm 49$ & $110 \pm 19$ \\
\hline
\end{tabular}

$\star$ GTS $=$ Glucose tolerance sum: sum of blood glucose values at fasting, 30, 60, and 120 minutes after oral glucose administration.

Though high fasting FFA values have been widely reported in obesity (Dole, 1956; Corvilain et al., 1961; Goldberg and Gordon, 1962), some disagreement is still present (Klein et al., 1965). The mean fasting FFA value for the whole group was substantially higher than that estimated in a group of normal children (mean $\pm S D, 650 \pm 171$ $\mu \mathrm{Eq} / 1 ., \quad \mathbf{n}=53$, unpublished observations) and those reported for children and adults by Corvilain et al. (1961). The mean of fasting glycerol values however, while higher than that of normal children (mean $\pm \mathrm{SD}, 98 \pm 51 \mu \mathrm{M} / \mathrm{l} ., \mathrm{n}=52$, unpublished observations) and normal adults (Meuller and Evans, 1963), was less clearly separated from the normal range.

High basal FFA and glycerol values in serum have been regarded as an expression of increased basal lipolysis (Vaughan, 1962; Björntorp and Hood, 1966; Carlson and Hallberg, 1968). Bagdade, Port, and Bierman (1969) have reported correlation between basal levels of both FFA and glycerol and glucose tolerance. This correlation was significant in obese subjects, but not in nonobese subjects, whether diabetic or non-diabetic. Those children in our series with 2-hour glucose levels greater than $110 \mathrm{mg} / 110 \mathrm{ml}$, and who may thus have some evidence of reduced glucose tolerance associated with their obesity, were con-

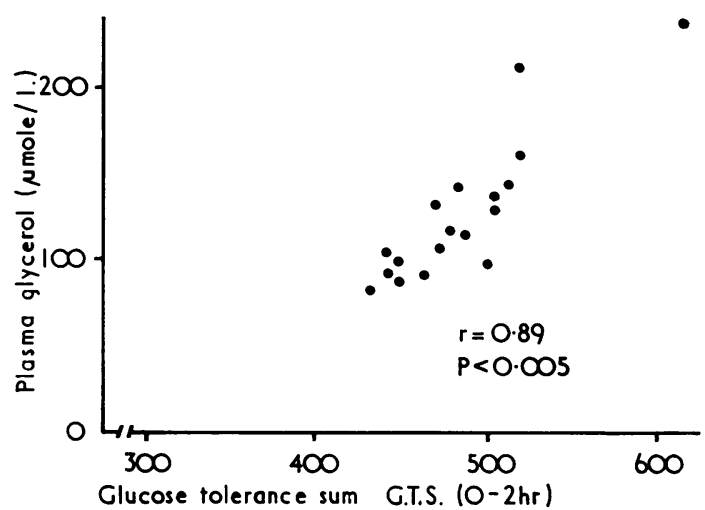

FIG. 3.-Plasma glycerol values plotted against glucose tolerance sums (GTS 0-2 hours) for obese children who had blood glucose values above $110 \mathrm{mg} / 100 \mathrm{ml} 2$ hours after oral glucose.

sidered in the light of this reported correlation. Fig. 3 expresses the relation of fasting glycerol values to glucose tolerance sum and shows a significant correlation. Children with glucose values less than $110 \mathrm{mg} / 100 \mathrm{ml}$ showed no such correlation, thus supporting the proposition that obesity associated with carbohydrate intolerance is characterized by increased basal lipolysis. Both FFA and glycerol values showed a uniform response to glucose with a steady fall to a remarkably narrow range of values at $1 \frac{1}{2}$ to 2 hours (Fig. 1). Stuchlíková et al. (1961) reported similar observations of FFA response to glucose in obesity. Our results do not support the suggestion of Gordon et al. (1963) and Kneebone (1965), that some obese subjects show an impaired response of FFA to a glucose load. The observed fall in FFA concentrations after glucose may be taken to imply an unimpaired ability for re-esterification in obesity (Shapiro, Chowers, and Rose, 1957). Parallel falls in glycerol in our study suggest that profound suppression of lipolysis had also occurred (Vaughan, 1962).

During the latter part of the GTT, from 2 to 4 hours both FFA and glycerol values returned to fasting levels. From 4 to 5 hours FFA values continued to rise, exceeding fasting levels in 25 cases. Most children in whom this rise above fasting levels did not occur had very high fasting FFA values initially. Glycerol values within the whole group stabilized between 4 to 5 hours (Fig. 1).

\section{Conclusion}

These observations on 46 obese children have revealed some borderline abnormalities of glucose tolerance. 7 children had equivocal values of 
GTS and 27 children had values of glucose at 120 minutes in excess of $110 \mathrm{mg} / 110 \mathrm{ml}$. Thus it is apparent that the increased incidence of glucose intolerance associated with obesity in adults occurs also in obesity in children. There was no clear relation between impairment of glucose tolerance and age of the child, degree, or duration of the obesity.

Fasting FFA values were high compared to nonobese children and adults. The higher values of fasting glycerol within our group were associated with impairment of glucose tolerance. This may suggest that there is increased basal lipolysis in these children.

Levels of FFA and glycerol showed a uniform response to oral glucose, falling to a narrow range of values between $1 \frac{1}{2}$ to 2 hours. No evidence for impaired suppression of lipolysis was found, nor was there any suggestion that responses could be separated into groups. Thus no support is provided for the concept that a separate group of children with a metabolic abnormality leading to obesity can be revealed by the response of FFA to oral glucose.

\section{REFERENCES}

Bagdade, J. D., Porte, D., Jr., and Bierman, E. L. (1969). The interaction of diabetes and obesity on the regulation of fat mobilization in man. Diabetes, $18,759$.

Björntorp, P., and Hood, B. (1966). Studies on adipose tissue from patients with or without diabetes mellitus. Acta Medica Scandinavica, 179, 221.

Carlson, L. A., and Hallberg, D. (1968). Basal lipolysis and effects of norepinephrine and prostaglandin $\mathrm{E}_{1}$ on lipolysis in human subcutaneous and omental adipose tissue. Fournal of Laboratory and Clinical Medicine, 71, 368.

Corvilain, J., Loeb, H., Champenois, A., and Abramow, M. (1961). Effect of fasting on levels of plasma-nonesterified fatty acids in normal children, normal adults, and obese adults. Lancet, 1 , 534.

Danowski, T. S., Aarons, J. H., Hydovitz, J. D., and Wingert, J. P. (1970). Utility of equivocal glucose tolerances. Diabetes, $19,524$.

Dole, V. P. (1956). A relation between non-esterified fatty acids in plasma and the metabolism of glucose. Fournal of Clinical Investigation, 35, 150.
Fajans, S. S., and Conn, J. W. (1959). Early recognition of diabetes mellitus. Annals of the New York Academy of Sciences, 82, 208.

Fajans, S. S., and Conn, J. W. (1965). Prediabetes, subclinical diabetes and latent clinical diabetes: interpretation, diagnosis and treatment. In On the Nature and Treatment of Diabetes (International Diabetes Federation, 5th Congress. Excerpta Med. Int. Congr. Ser., No. 84), p. 641. Ed. by B. S. Leibel and G. A. Wrenshall. Excerpta Medica Foundation, Amsterdam.

Goldberg, E. M., and Gordon, E. S. (1962). Free fatty acid metabolism in human obesity. (Abst.) Fournal of Laboratory and Clinical Medicine, 60, 877.

Gordon, E. S. (1962). Relationship between obesity and diabetes mellitus. Metabolism: Clinical and Experimental, 11, 819.

Gordon, E. S., Goldberg, M., and Chosy, G. J. (1963). A new concept in the treatment of obesity. Fournal of the American Medical Association, 186, 50.

Klein, R. F., Troyer, W. G., Baek, K. W., Hood, T. C., and Bogdonoff, M. D. (1965). Lipid mobilization in lean and obese subjects. Annals of the New York Academy of Sciences, 131, 662.

Kneebone, G. M. (1965). A biochemical, clinical and nutritional assessment of childhood obesity. Australian Paediatric fournal, $1,120$.

Laurell, S., and Tibbling, G. (1968). The use of blood glycerol determination in the diagnosis of hyperthyroidism. Clinica Chimica Acta, 21, 127.

Morse, W. I., Sidorov, J. J., Soeldner, J. S., and Dickson, R. C. (1960). Observations on carbohydrate metabolism in obesity. Metabolism: Clinical and Experimental, 9, 666.

Mueller, P. S., and Evans, W. H. (1963). Responses of plasma glycerol concentrations to epinephrine, norepinephrine, glucose, insulin, and prolonged fasting in man. fournal of Laboratory and Clinical Medicine, 61, 953.

Mullins, A. G. (1958). The prognosis in juvenile obesity. Archives of Disease in Childhood, 33, 307.

Novák, M. (1965). Colorimetric ultramicro-method for the determination of free fatty acids. Fournal of Lipid Research, 6, 431

Schalch, D. S., and Kipnis, D. M. (1965). Abnormalities in carbohydrate tolerance associated with elevated plasma nonesterified fatty acids. Fournal of Clinical Investigationi, 44, 2010.

Shapiro, B., Chowers, I., and Rose, G. (1957). Fatty acid uptake and esterification in adipose tissue. Biochimica et Biophysica Acta, 23, 115.

Stuchliková, E., Hrušková, J., Tenorová, M., Novotná, B., Komárková, A., and Riedl, O. (1961). Some changes in intermediary metabolism in obese patients. Clinica Chimica Acta, 6, 571 .

Tanner, J. M., and Whitehouse, R. R. (1962). Standards for subcutaneous fat in British children. British Medical fournal, 1, 446.

Vaughan, M. (1962). The production and releases of glycerol by adipose tissue incubated in vitro. Fournal of Biological Chemistry, 237, 3354.

Correspondence to Dr. J. M. Court, Department of Paediatrics, University of Melbourne, Royal Children's Hospital, Parkville, Victoria 3052, Australia. 